
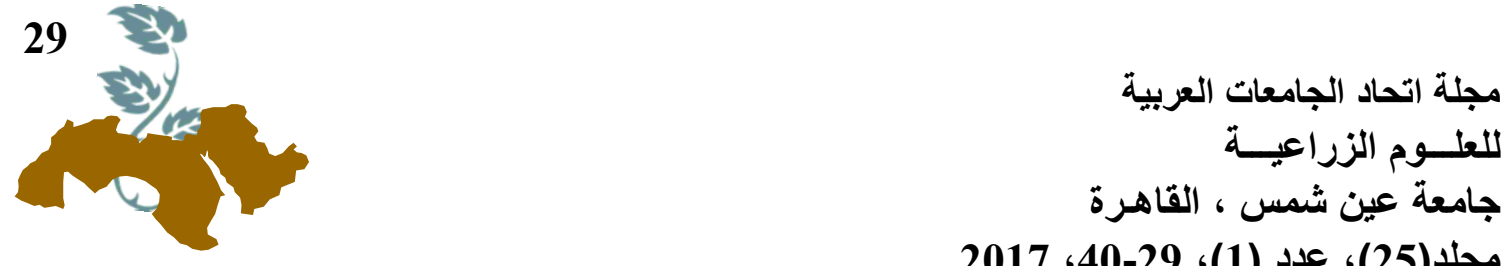

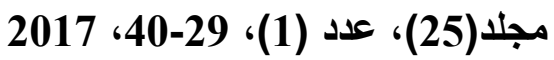

الاحتياجات الإرشادية لمزارعي سهل الطينة فيما يتعلق بالإدارة المتكاملة للأراضي عالية الملوحة

[2]

\author{
حماده تحمه إبراهيم - أحمد عثمان بدوى \\ شعبة الدراسات الاقتصادية والاجتماعية - قسم الإرشاد الزراعي - مركز بحوث الصحراء - القاهرة - مصر \\ E-mail: ahmedwasel48@Gmail.com
}

استخدم البحث العرض الجدولي بالتكرارات والنسب

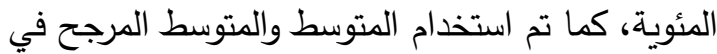

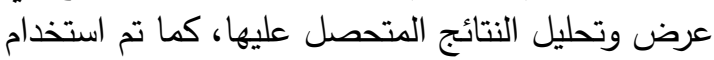

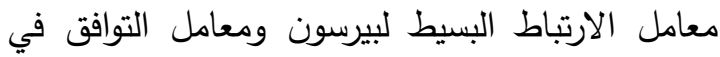

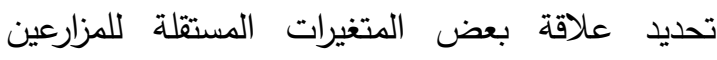
المبحوثين بمستواهم المعرفي المتعلق بالادارة المتكاملة المزينة

$$
\text { للاراضي الملحية. }
$$

$$
\text { وقد اسفرت اهم نتائج الدراسة عن }
$$

- انخفاض المستوى المعرفي لمزارعي المنطقة فيما يتعلق بزراعة وادارة الاراضي المتأثرة بالملوحة. لترئ.

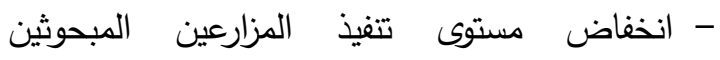
لتوصيات الادارة المتكاملة للاراضي الملحية.

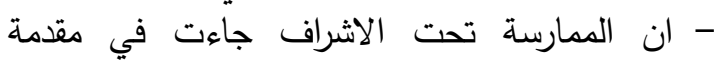

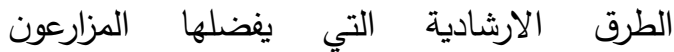

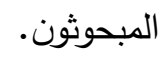
- وجود علاقة ارتباطية معنوية بين كل من المتغيرات

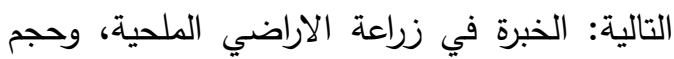

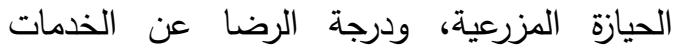

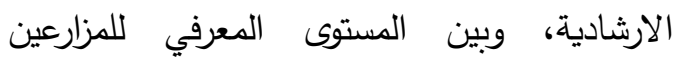
المبحوثين فيما يتعلق بالادارة المتكاملة للاراضي لإني

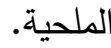

الكلمات الدالة: الاحتياجات الإرشادية، سهل الطينة

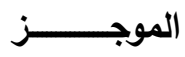

استهدف البحث التعرف على المستوى المعرفي

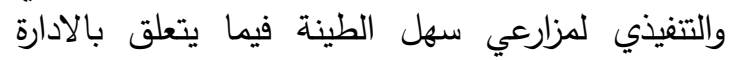

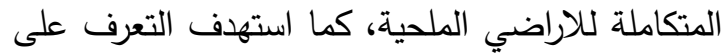
الطرق الارشادية التي يفضلها مزارعو سهل الطينة في

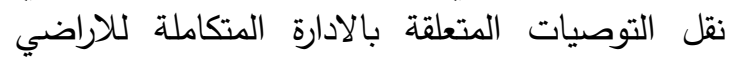

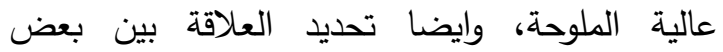
المتغيرات المستقلة لمزارعي سهل الطينة المبحوثين

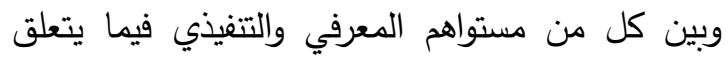
بالادارة المتكاملة للاراضي عالئ علية الملوحة.

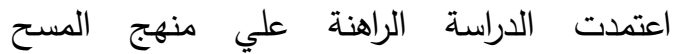

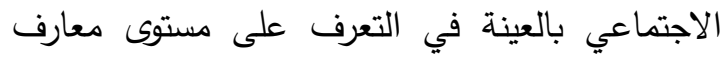
وتتفيذ المزارعين لتوصيات الادارة المتكاملة للاراضي

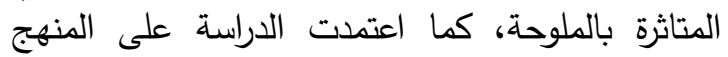

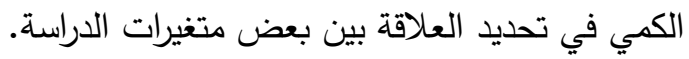

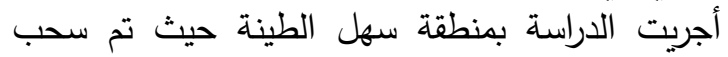

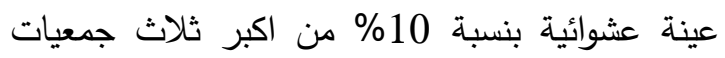

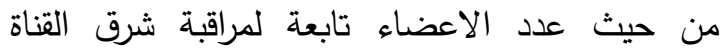

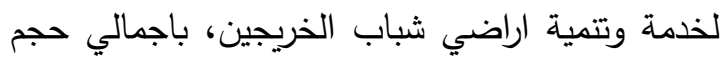

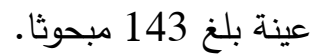

(تسليم البحث فى 7 سبمتبر 2016) (مراجعة البحث فى 16 نوفمبر 2016) (الموافقة على البحث فى 18 ديسمبر 2016) نوفير 
من حيث درجات حرارة معتدلة ورطوبة نسبية ملائمة

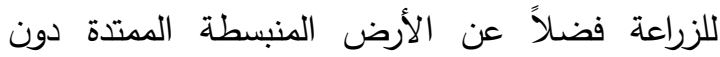
ارتفاعات أو منخفضات تعوق عملية الأستصلاح والاستزراع بالإضافة إلي وجود مياه للري. (دراسة رصات رصد

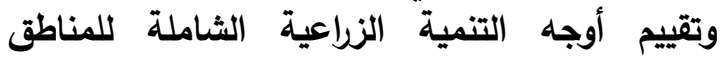

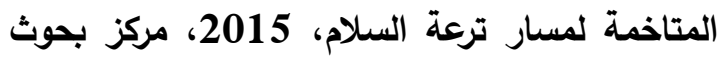
الصحراء، ص صنار تر-3).

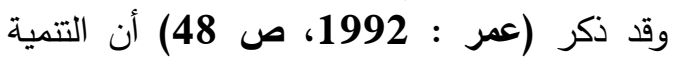
الزراعية هي التحول من طرق الإنتاج التقليدية إلى الى التية

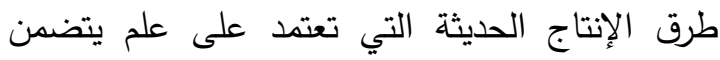
محتوى تقنى مثل الأصناف الجديدة، ولتئ وممارسات الميكنة الزراعية، والنظم المزرعية الجديدة والاستغادة الإنات

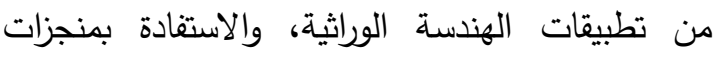

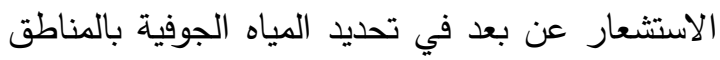

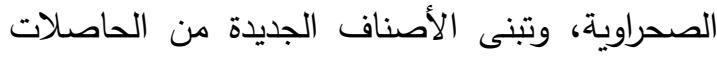

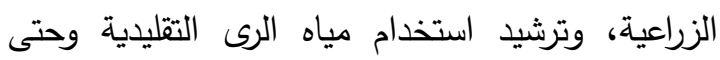
يتبنى الزراع تلك الممارسات الموصى بهاه المئه فان الأمر

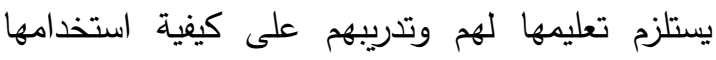
بكفاءة في مزارعهم وهذا التحول هو لب التمية الزراعية

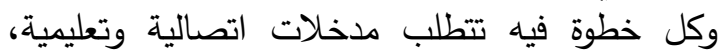

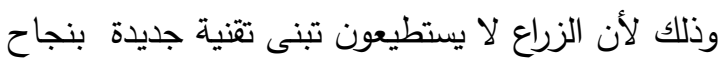

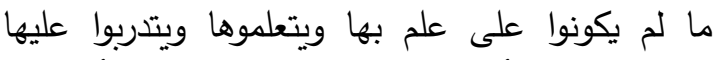

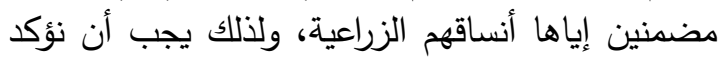

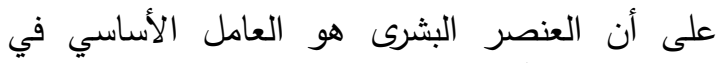

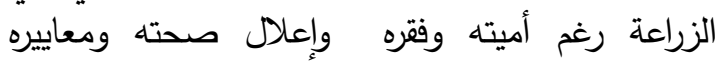

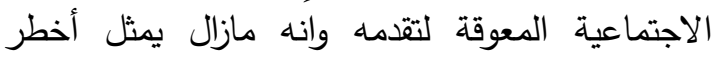

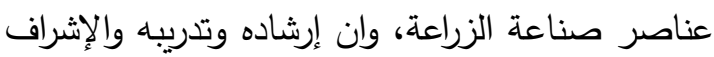

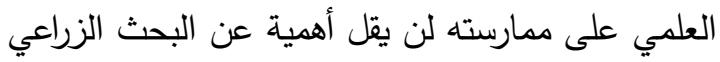

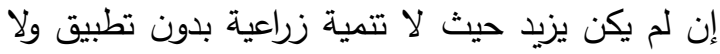
تطبيق بدون فلاح. ولذا تقع المسؤلية الكبرى على جهاز الإرشاد

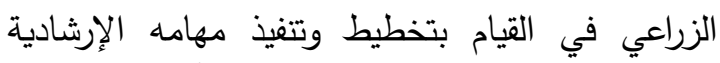

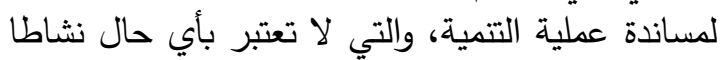

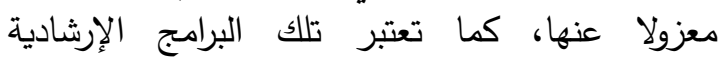
والمشروعات الإرشادية والمرشدين الزراعيين جزءاً من الرئي عملية تتمية المجتمعات الزراعية المستحدثة.

واوضح (Francis and Carter, 2001) حاجة المزارعين المتزايدة للحصول على المعلومات التطبيقية في مجال الزراعة وأهمية توفير القدرات التعات
- وجود علاقة تأثيرية ذات معنى بين كل من: الحالة

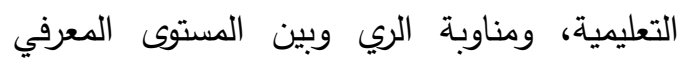
للمزارعين المبحوثين المتعلق بالادارة المتكاملة

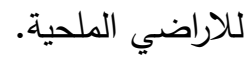
- وجود علاقة ارتباطية معنوية بين كل من المتغيرات

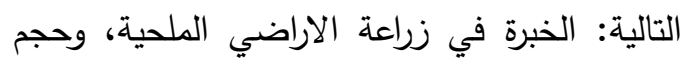

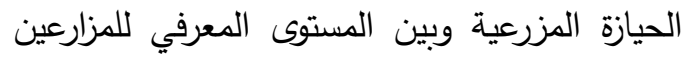
المبحوثين فيما يتعلق بالادارة المتكاملة للاراضي المزين الملحية. - المئن - وجود علاقة تأثيرية ذات معنى بين كل من: الحالة

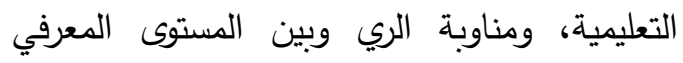
للمزارعين المبحوثين المتعلق بالادارة المتكاملة لكلاراضي الملحية. وفي نهاية البحث ووفقا للنتائج المتحصل عليها تم

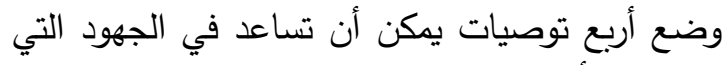
تستهدف تأهيل المزارعين فيما يتعلق بالادارة المتكاملة للاراضي الملحية بمنطقة الدراسة.

\section{المقدمـة}

بذلت الدولة مجموعة من الجهود لتنمية سيناء لعل أبرزها البدء في تحقيق مشروع ترعة السلام الذي لهين

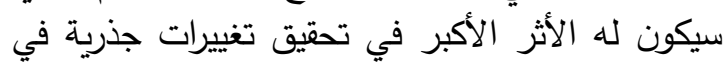

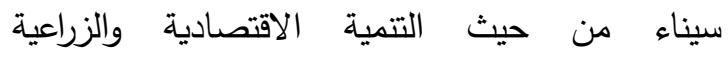
والاجتماعية والعمرانية، ويعتبر مشروع ترعة السلام أحد الأدية

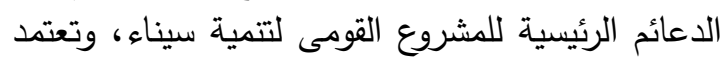

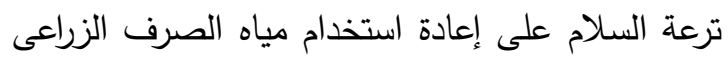

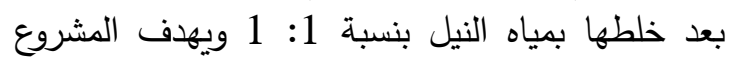
إلى استصلاح واستزراع 620 ألف فدان منها 1220

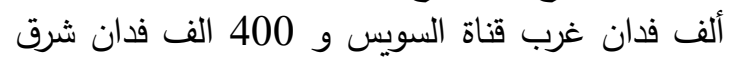
قناة السويس، تأتي منطقة سهل الطينة علي رأس الس الس المناطق التي يهدف مشروع ترعة السلام إلي تتميتها فهي أول المناطق في المرحلة الثانية من المشروع الثران بمساحة 50 ألف فدان وهي الجئ الجزء التابع إدارياً

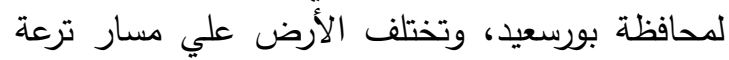
السلام في خواصها وتركييها ودرجة قابليتها للزراعة لإنة حيث نجد أن أرض سهل الطينة معظمها طينية ثقيلة

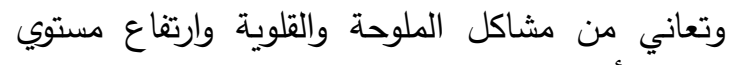
الماء الأرضي وتتمتع المنطقة بظروف مناخية مناسبة 
بناءاً علي أهمية دور الإرشاد في تغيير العادات

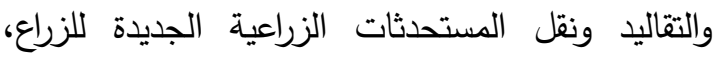

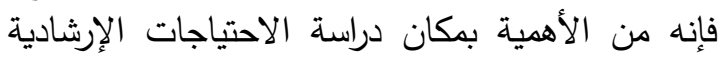

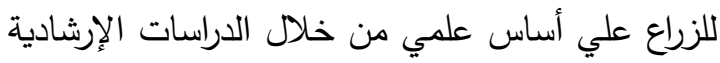

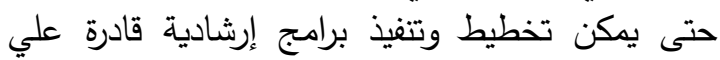

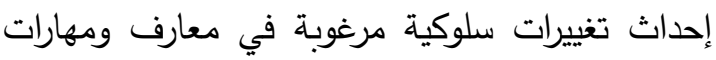

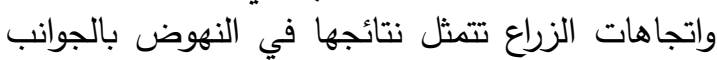

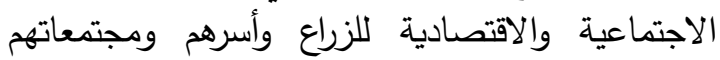

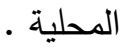

\section{المشكلة البحثية}

انطلاقا من العرض السابق يمكن حصر مشكلة الدراسة في محاولة الاجابة على التساؤلات التالية:

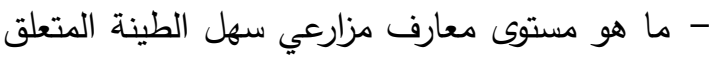

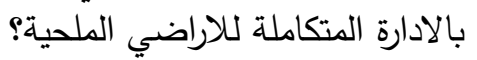

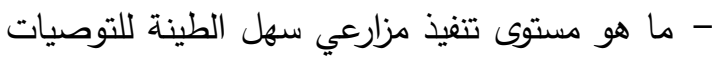

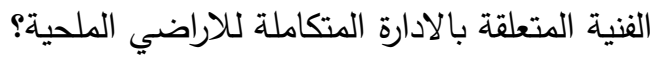

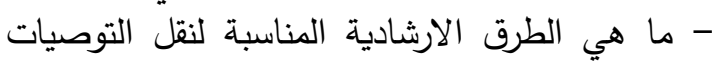
الفنية المتعلقة بالادارة المتكاملة للاراضي الملحية؟ لإنية لإني

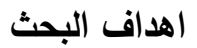

من خلال العرض السابق لمشكلة الدراسة يمكن تحديد الاهداف البحثية فيما يلي: 1-تحديد مستوى معارف مزارعي سهل الإنه الطينة فيما يتعلق بالإدارة المتكاملة للأراضي عزاري عالية الملوحة.

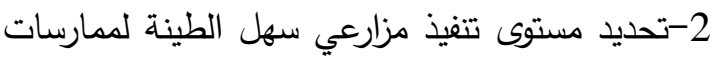
3الإدارة المتكاملة للأراضي عالية الملوحة.

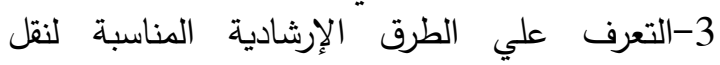
التوصيات الإرشادية المتعلقة بالإدارة المتكاملة لكأراضي عالية الملوحة.

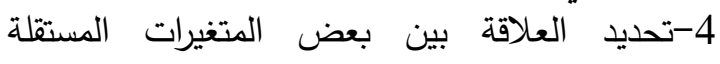

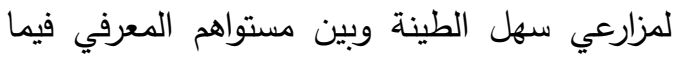

يتعلق بالإدارة المتكاملة للأراضي عالين الئة الملوحة. 5-تحديد العلاقة بين بعض الإداكلة المتغيرات المستقلة

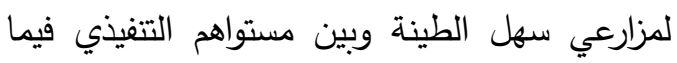
يتعلق بالإدارة المتكاملة للأراضي عالية الملوحة.
اللازمة للمؤسسات الارشادية لكي تستطيع ان تستجيب

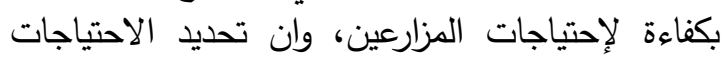

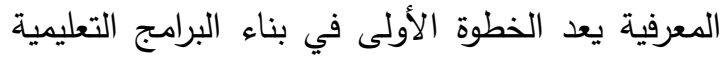

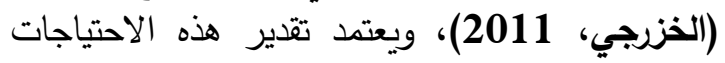

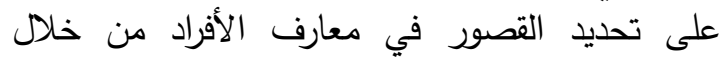

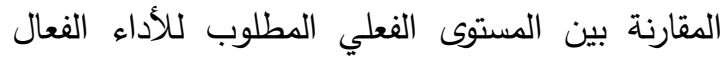

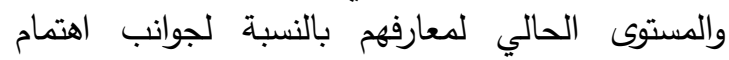
عمهم (Boydell, 1990). لذا فمن الضروري أن يكون توجه البرامج الإرشادية

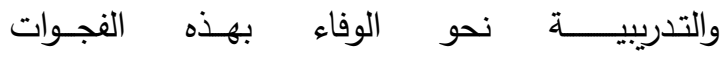

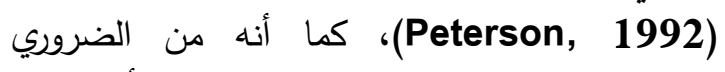
الاهتمام بتقدير الاحتياجات الارشادية من أجل بناء الناء

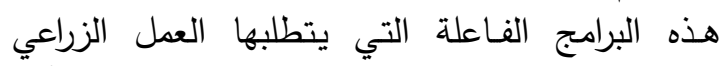

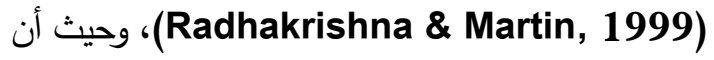
العمل الإرشادي هو عمل ذو اتجاهين، يقوم بنقل

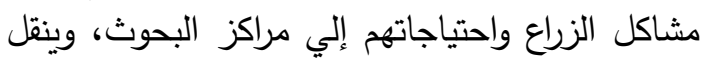

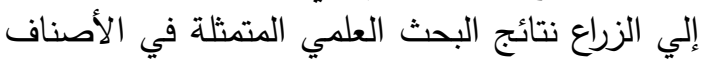
والتقنيات الحديثة في الزراعة وكذلك التوصيات التئ التئي

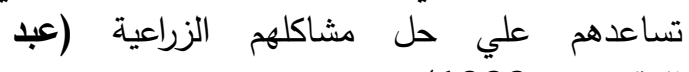
(المقصود، 1988) - (198). لذا فإن التعرف علي أهم المشاكل التي يعاني منها

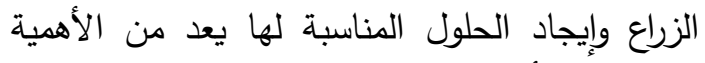

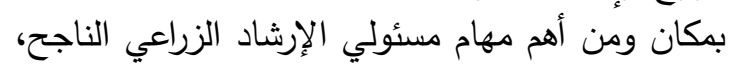

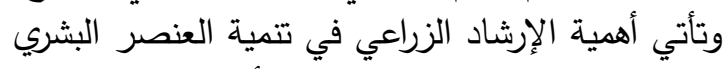

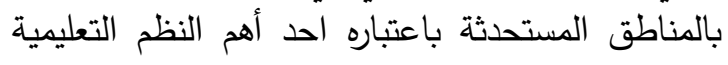

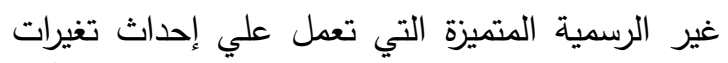

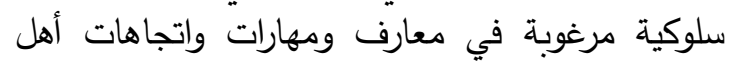

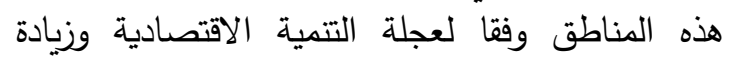

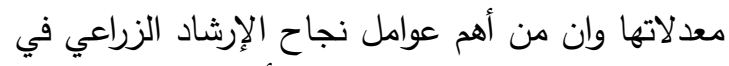

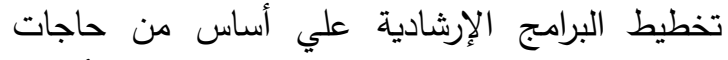

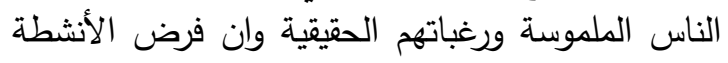

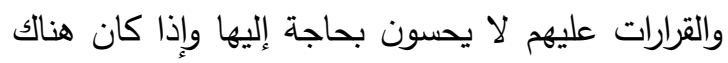

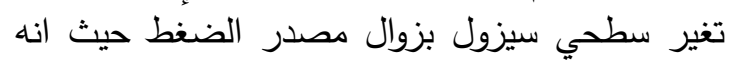

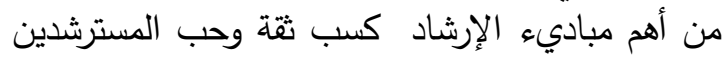

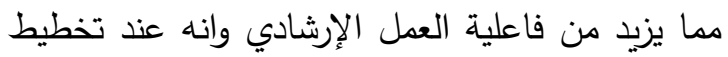

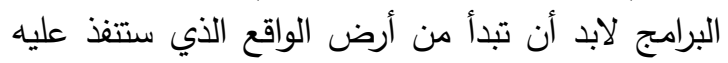

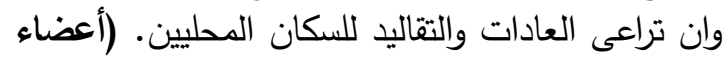

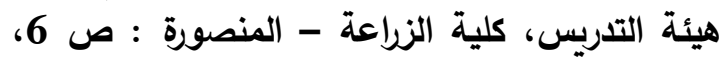

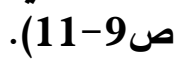


ولتحقيق الهدف الخامس من اهداف البحث تم

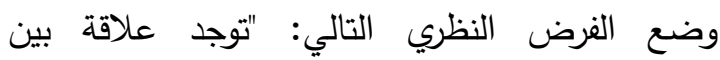
المتغيرات المستقلة للمزارعين المبحوثين وبين مستواهم

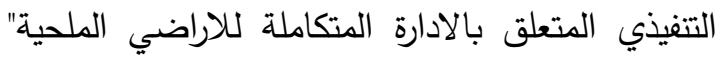

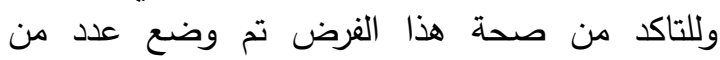
الفروض الاحصائية (من 13 - 24) تشترك في مقولة

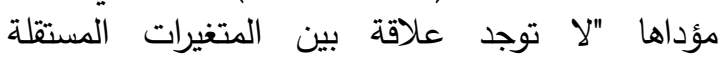

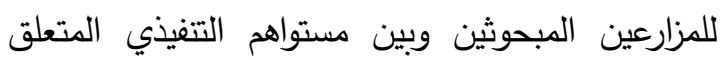
بالادارة المتكاملة للاراضي الملحينة وبين ملتحاهي

$$
\text { 3-أدوات التحليل الاحصائي }
$$

استخدم البحث العرض الجدولي بالتكرارات والنسب

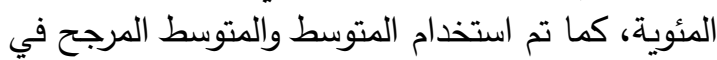

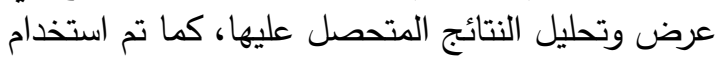
معامل الارتباط البسيط لبيرسون ومعامل التوافق التقان

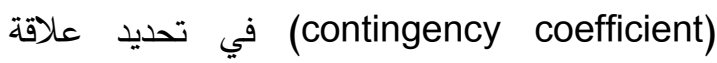
بعض المتغيرات المستقلة للمزارعين المبحوثين بمستواهم المعرفي والتتفيذي المتعلق بالادارة المتكاملة للاراضي الميتي بداري

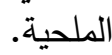

\section{4-الطريقة البحثية}

$$
\text { أ- منهج الدراسة }
$$

اعتمدت الاراسة الراهنة علي منهج المستح

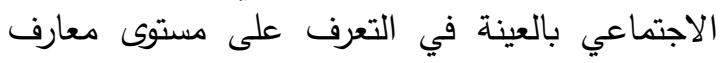

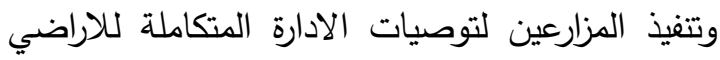

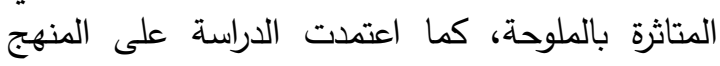
الكمي في تحديد العلاقة بين بعض متغيرات العتدرة الدراسة.

\section{ب- - مينة الدراسة}

استخدمت الدراسة الراهنة أسلوب البحث الميداني

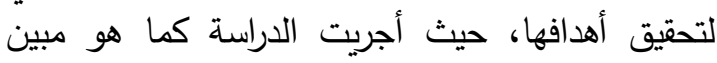

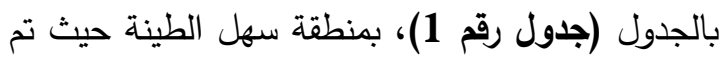

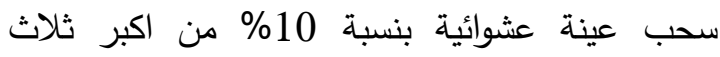
جمعيات من حيث عدد الاعضاء تابعة لمراقبة شرق

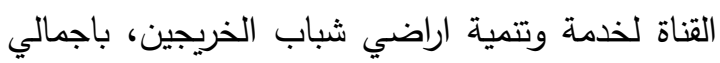
حجم عينة بلغ 143 مبحوثا.
خطة الاراسة

لإنجاز الأهداف السابق عرضها تم وضع خطة اشتملت الدراسة بموجبها علي العناصر التالية: 1-مفهوم الادارة المتكاملة للاراضي الملحية.

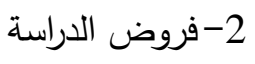
3- ادوات التحليل الاحصائي. 4- الطريقة البحثية. 5- 5- 5ائج الدراسة.

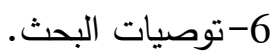

1-مفهوم الادارة المتكاملة للأراضي الملحية: تشكل

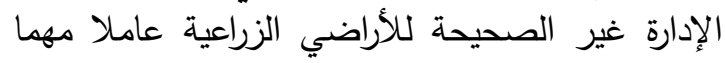

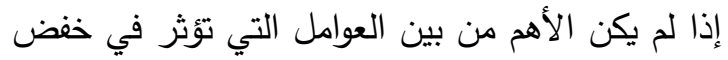

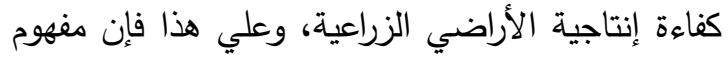

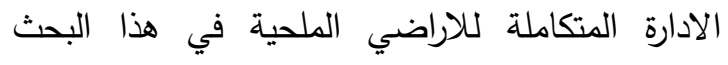

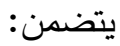

المعارف والممارسات الخاصة بتحسين خواص

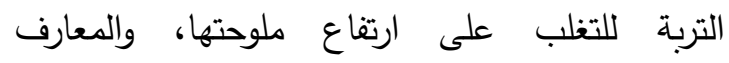
والممارسات المتعلقة بزراعة وخدمة محاصيل تتاسب

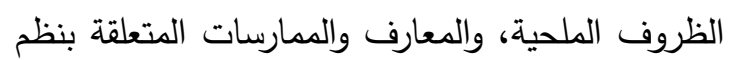

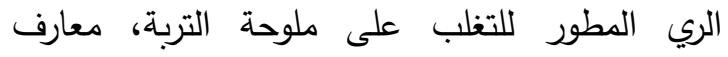

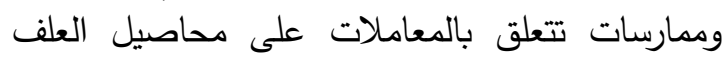

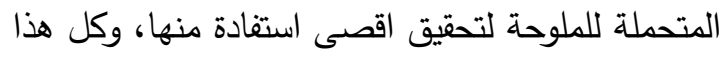

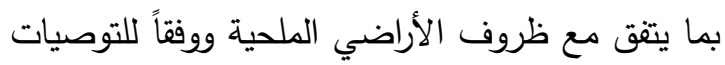

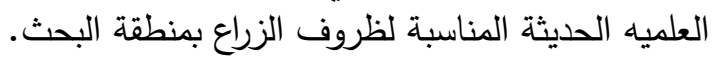

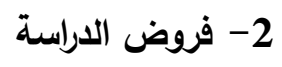

لتحقيق الهدف الرابع من اهداف البحث تم وضع

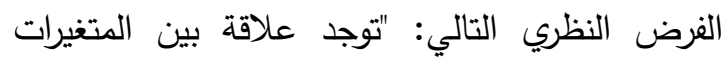
المستقلة للمزارعين المبحوثين وبين مستواهم المعرفي لتئي

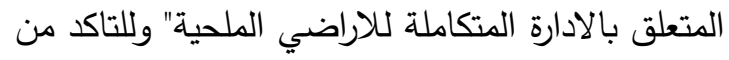

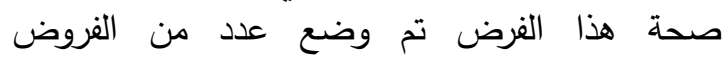
الاحصائية (من 1 - 12) تشترك في مقولة مؤداها "لا

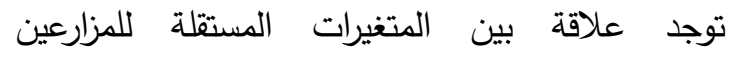

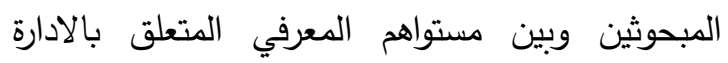
المتكاملة للاراضي الملحية". 
جدول 1. حصر بمساحات وعدد اعضاء الجمعيات التابعة لمراقبة شرق القناة لخدمة وتتمية اراضي شباب الخريجين

\begin{tabular}{|c|c|c|c|c|c|}
\hline حجم العينة & عدد الاعضاء & المساحة بالفدان & النطاق الجغرافي & الجمعية & م \\
\hline 46 & 459 & 4595 & سهل الطينة & قرية 7 & 1 \\
\hline 41 & 406 & 4068 & سهل الطينة & قرية 4 & 2 \\
\hline \multirow[t]{7}{*}{56} & 566 & 2619 & سهل الطينة & الوحدة المشتركة & 3 \\
\hline & 185 & 1855 & القنطرة شرق & الفيروز & 4 \\
\hline & 340 & 2275 & القنطرة شرق & مدين قاسم & 5 \\
\hline & 332 & 3320 & القنطرة شرق & صالح سليمان عودة & 6 \\
\hline & 313 & 3130 & القنطرة شرق & عبد ربه حمادة 1 & 7 \\
\hline & 243 & 2432 & القنطرة شرق & عبد ربة حمادة 2 & 8 \\
\hline & 117 & 1150 & القنطرة شرق & عباد الرحمن & 9 \\
\hline 143 & 2961 & 25444 & & جملـــة & \\
\hline
\end{tabular}

المصدر: مراقبة شرق القناة، المشروع القومي لخدمة وتتمية اراضي شباب الخريجين

6-حجم الحيازة المزرعية: وتم التعبير عنها بعدد الأفدنة التي يقوم المبحوث بزراعتها وقت جمع بيانات البحث. - (الافنة

7-مناوبة الري: وتم التعبير عنه بعدد الأيام المنقضية 8ين كل ريتين متتاليتين. 8-درجة عضوية المنظمات الاجتماعية: وتم التهن التعبير

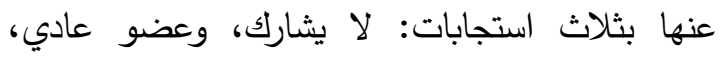

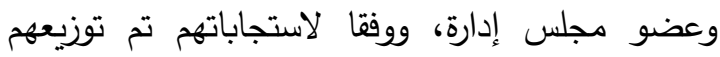

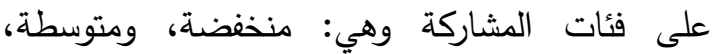

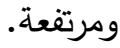
9-النشأة: وتم التعبير عنها بإحدى الاستجابتين:

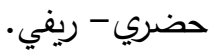
10-درجة الرضا عن الخدمات الإرشادية: تم وضع

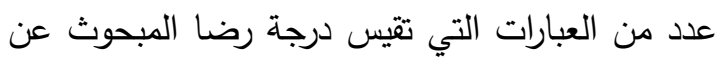

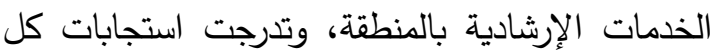

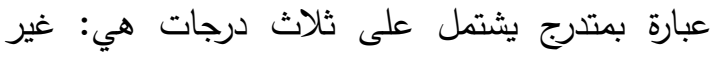

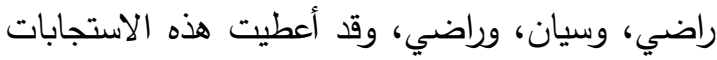

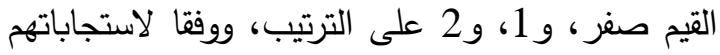

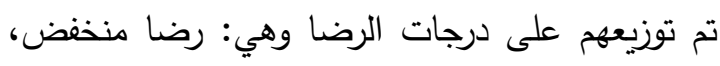
ورضا متوسط، ورضا مرتفع.
وقد تم تصميم استمارة استبيان جمعت بالمقابلة pre- الثخصية، وذلك بعد إجراء الاختبار المبدئي عليها للتأكد من صحة العبارات ومدى مناسبتها لتحقيق أهداف البحث لتصبح الاستمارة في صورتها النهائية والتي اشتملت على الأجزاء التالية. أولا: المتغيرات الثخصية للمزارعين المبحوثين 1-السن: وتم التعبير عنه بعمر المبحوث لأقرب سنة وقت جمع البيانات . 2-الحالة التعليمية: وتم التعبير عنها بالاستجابات التالية: يقرأ ويكتب ،واعدادية، ومؤهل متوسط، ومؤهل 3-عدد أفراد الأسرة: وتم التعبير عنه بعدد أفراد

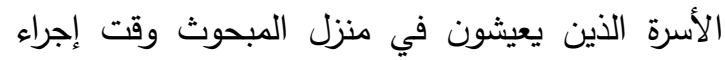

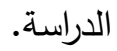
4-ممارسة مهنة الزراعة قبل استلام الارض: وتم

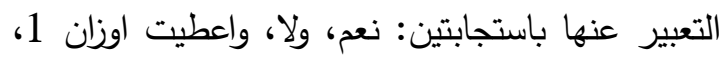
وصفر على الترتيب. 5-الخبرة في زراعة الأراضي الملحية: وتم التعبير

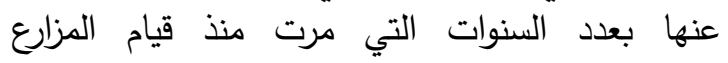
المبحوث بالزراعة بمنطقة الدراسة. 
رابعا: الطرق الإرشادية المناسبة لنقل التوصيات الإرشادية من وجهة نظر المزارعين المبحوثين

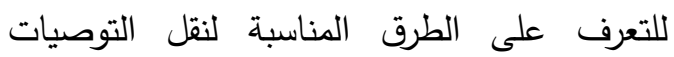

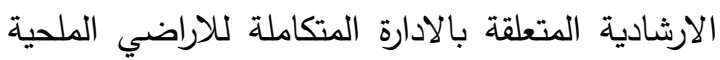

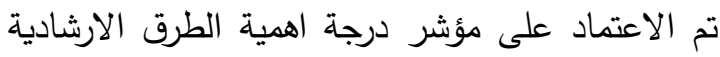

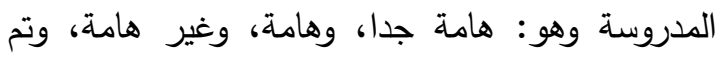

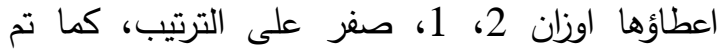

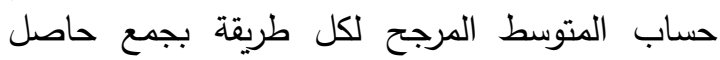

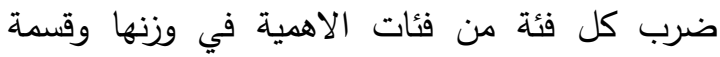
المجموع على عدد افراد العينة مضروبا في 2 (الدرجة

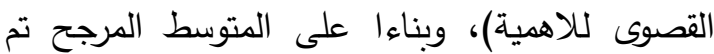
ترتيب الطرق الارشادية المدروسة من حيث الطيا درجة تفضيل المزارعين المبحوثين لها.

نتائسـج الاراســة

أولا: خصائص المزارعين المبحوثين

توضح نتائج الجدول رقم (2) بعض خصائص المزارعين المبحوثين، ويمكن تلخيص أهم معالم تلك بلك المتغيرات فيما يلي: - المزئ المين 1- أكثر من نصف فيمات المزارعين المبحوثين (60,8\%) يقعون في الفئة العمرية المتوسطة (من 40-50 المارئ (80) عام).

2- أكثر من نصف المزارعين المبحوثين (57.3\%) يقعون في فئة يقرا ويكتب، كما بلغت نسبة فئة الحاصلين على مؤهل متوسط 35,7\%، في في حين في

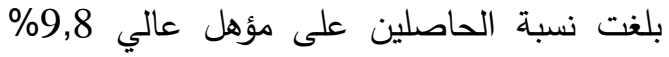
فقط من المزارعين المبحوثين. 3- تراوح حجم الاسرة للغالبية العظمى من المزين. المبحوثين (95,1\%) ماوح ها بين متوسطة الى كبيرة

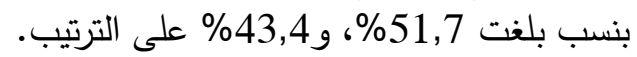
4- بلغت نسبة المزارعين الذين سبق لهم ممارسة مهنة

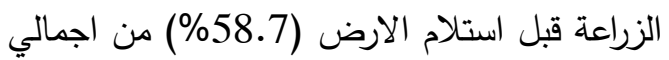
عدد المزارعين المبحوثين. 5- توزع جميع المزارعين المبحوثين على فئتي الخبرة

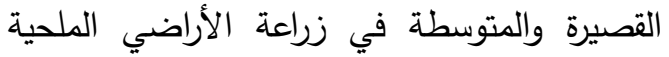

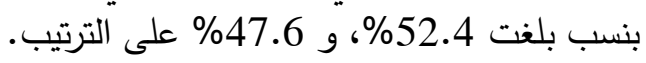

11-التجديدية: وتم التعبير عنها بثلاث استجابات

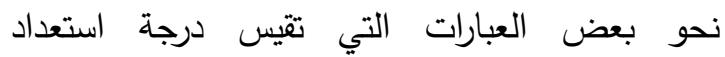
المزارعين المبحوثين لتقبل المستحدثات الزراعية، ووفقات

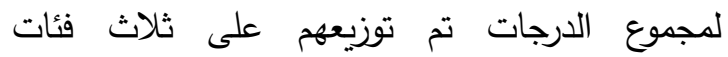
ل ل لتجديدية.

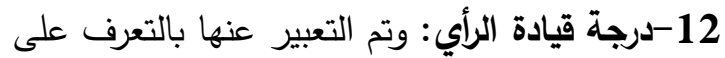
استجابات الزراع نحو بعض إدادة العبارات التي تقيس درجة التعات

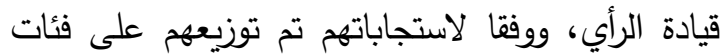
قيادة الرأي وهي: منخفضة، ومتوسطة، لائهة ومرتفعة.

ثانيا: المستوى المعرفي للمزارعين المبحوثين فيما يتعلق بالادارة المتكاملة للّاراضي الملحية لمئي

وقد استخدمت الدراسة عدة أساليب لقياس المستوى المعرفى للمزارعين المبحوثين فيما يتعلق بالتوصيات

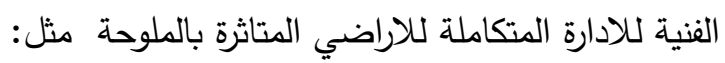

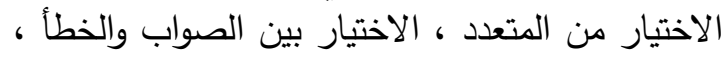

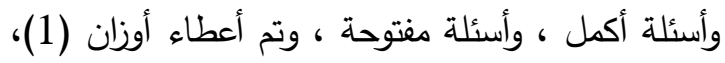

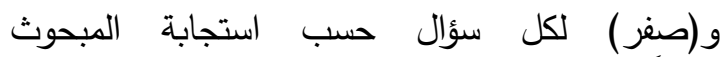
ووفقاً لذلك تم توزيع المبحوثين على فئات المستوى المئه

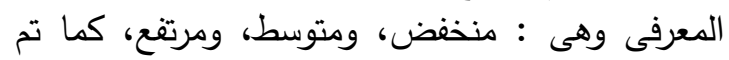

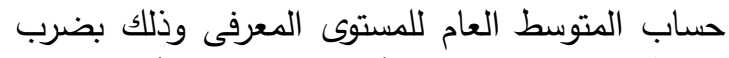

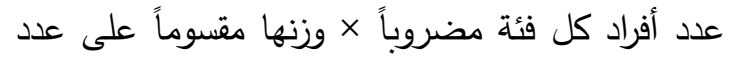

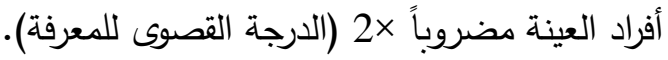

ثالثا: مستوى تنفيذ المزارعين المبحوثين لتوصيات الادارة المتكاملة للاراضي الملحية تلفيذ المزارعين

وقد تم وضع مجموعة من التوصيات الفنية المتعلقة بالادارة المتكاملة للاراضي الملحية وتم سؤال المزارعين

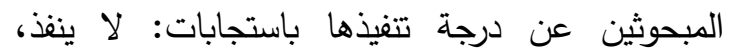

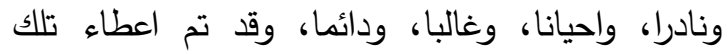

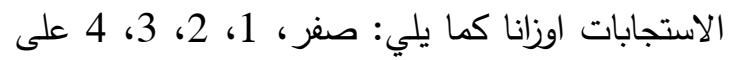

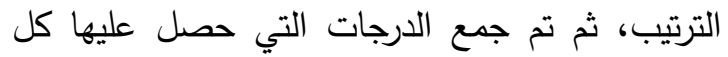
مبحوث وبناءا عليه تم توزيعهم على فئات التنفيذ:

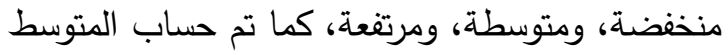

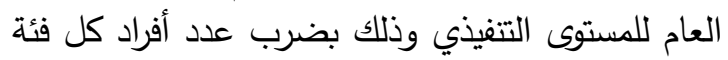

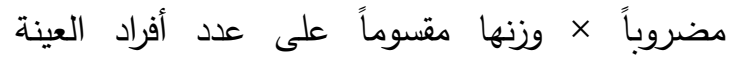
مضروباً ×2 (الدرجة القصوى للتنفيذ). 

الاحتياجات الإرشادية لمزارعي سهل الطينة فيما يتعلق بالإدارة المتكاملة للأراضى عالية الملوحة

جدول 2. توزيع المبحوثين وفقا للمتغيرات الشخصية المدروسة

\begin{tabular}{|c|c|c|c|c|c|}
\hline$\%$ & عدد & المتغير & $\%$ & عدد & المتغير \\
\hline \multicolumn{3}{|c|}{ حجم الحيازة المزرعية } & \multicolumn{3}{|r|}{ السن } \\
\hline 19,6 & 28 & (اقل من 10 فدان) & 30,8 & 44 & (اقل من 40 عام) \\
\hline 75,5 & 108 & (من 10-اقل من 20 فدان) & 60,8 & 87 & (من 40 - اقل من 50) \\
\hline 4,9 & 7 & (20 فدان فأكثر) & 8,4 & 12 & (50 عام فأكثر ) \\
\hline \multicolumn{3}{|r|}{ | النشأة } & \multicolumn{3}{|c|}{ الحالة التعليمية } \\
\hline & & & 57,3 & 82 & يقرأ ويكتب \\
\hline 95,1 & 136 & ريفي & 7 & 10 & اعدادية \\
\hline 4,9 & 7 & حضري & 35,7 & 37 & مؤهل متوسط \\
\hline \multicolumn{3}{|r|}{ مناوبة الري } & 9,8 & 14 & مؤهل عالي \\
\hline 46,2 & 66 & \multirow{3}{*}{ 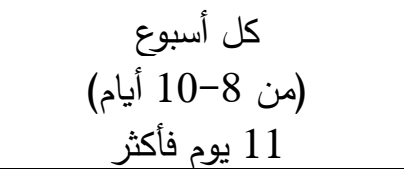 } & \multicolumn{3}{|c|}{ عدد أفراد الأسرة } \\
\hline 30,8 & 44 & & 4,9 & 7 & \multirow{3}{*}{ 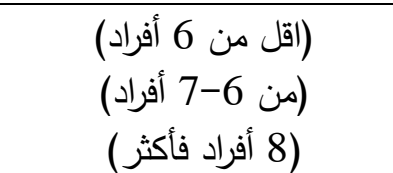 } \\
\hline 23,1 & 33 & & 51,7 & 74 & \\
\hline \multicolumn{3}{|c|}{ درجة عضوية المنظمات الاجتماعية } & 43,4 & 62 & \\
\hline 65 & 93 & (اقل من 3 درجات) & \multicolumn{3}{|c|}{ ممارسة مهنة الزراعة قبل استلام الارض } \\
\hline 28,7 & 41 & (من 3-5 درجات) & 58,7 & 84 & نعم \\
\hline 6,3 & 9 & (6 درجات فأكثر) & 41,3 & 59 & $\gamma$ \\
\hline \multicolumn{3}{|c|}{ درجة الرضا عن الخدمات الإرشادية } & \multicolumn{3}{|c|}{ الخبرة في زراعة الأراضي الملحية } \\
\hline 92,3 & 132 & منخفضة (اقل من 8درجات) & 52,4 & 75 & (اقل من 10 سنوات) \\
\hline 7,7 & 11 & متوسطة (من 8-14 درجة) & 47,6 & 68 & (من 10 - اقل من 20 سنة) \\
\hline 0 & 0 & مرتفعة (15 درجة فأكثر) & 0 & 0 & (20 سنة فأكثر) \\
\hline \multicolumn{3}{|r|}{ ل الدرجة قيادة الرأي } & \multicolumn{3}{|c|}{ التجديدية } \\
\hline 60,1 & 86 & منخفضة ( اقل من 5 درجة) & 57,3 & 82 & منخفضة ( اقل من 5درجات) \\
\hline 35 & 50 & متوسطة ( 5-8 درجات) & 35 & 50 & متوسطة ( من 5- 7درجات) \\
\hline 4,9 & 7 & مرتفعة (9 درجات فأكثر) & 7,7 & 11 & مرتفعة ( 8 درجات فأكثر) \\
\hline
\end{tabular}

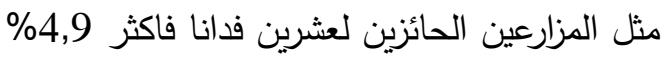
6- انخفاض درجة التجديدية لدى المزارعين المبحوثين فقط من اجمالي حجم عينة الدرسة. حيث توزع الغالبية العظمى لهم (192,3 8- الغالبية العظمى للمزارعين المبحوثين (95,1\%) ذوي نشأة ريفية.

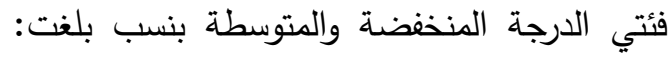

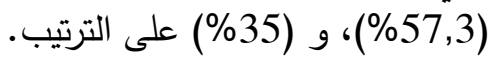

9- تراوحت درجة عضوية المنظمات الاجتماعية 7- أكثر من ثلاث ارباع المزارعين المبحوثين بقليل

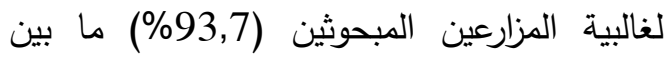
(\%75,5) يقعون في فئة حجم الحيازة المزرعية منخفضة الى متوسطة بنسب بلغت: 65\%؛ المتوسطة (من 10-اقل من 20 فدان)، في حين و28,7\% على الترتيب. 
ثالثا: مستوى تنفيذ المزارعين المبحوثين لتوصيات الادارة المتكاملة للاراضي الملحية

أوضحت نتائج الدراسة جدول رقم (4) انخفاض

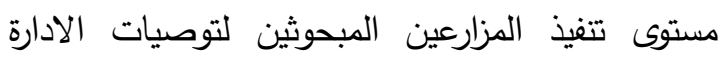

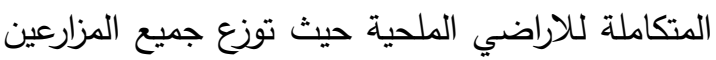

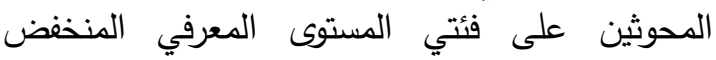

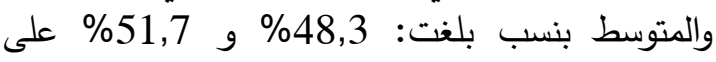
الترتيب، كما بلغ المتوسط العام لمستواهم التتفيذي

وتؤكد تلك النتائج على اهمية التركيز على الانشطة التدريبية الارشادية التي تستهدف رفع مهارات وقدات الترات

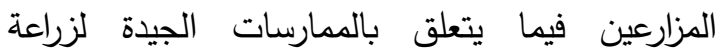

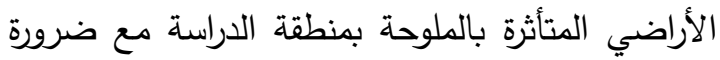

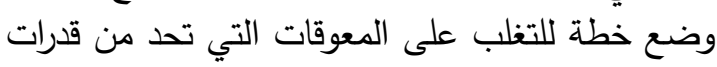
المزارعين في ادارة الأراضي الملحية.

جدول 4. توزيع المزارعين المبحوثين وفقا لمستواهم التتفيذي المتعلق بالادارة المتكاملة للاراضي الملحية

\begin{tabular}{|c|c|c|}
\hline$\%$ & $ت$ & المستوى التنفيذي \\
\hline 48.3 & 69 & مستوى منخفض (اقل من 8 درجات) \\
\hline 51.7 & 74 & مستوى متوسط (من 8 - 14 درجة) \\
\hline 0 & 0 & مستوى مرتفع (15 درجة فاكثر) \\
\hline \multicolumn{2}{|c|}{0,26} & المتوسط العام \\
\hline
\end{tabular}

الابعا: الطرق الإرشادية المناسبة لنقل التوصيات الإرشادية من وجهة نظر المزارعين المبحوثين

للتعرف على درجة تفضيل المزارعين المبحوثين للطرق الارشادية تم الاعتماد على مؤشر درجة لطفئ الهمية

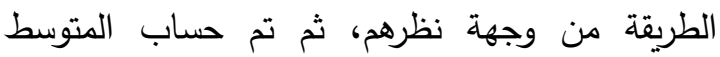
المرجح للاهمية.

وقد اظهرت نتائج البحث جدول رقات لاثم (5) ان

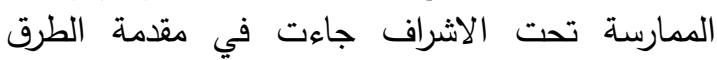

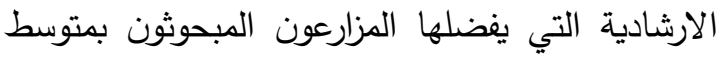
بلغ 0,74 ، يليها الزيارات الحقلية والافلام التعليمية

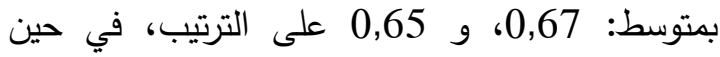
احتلت التسجيلات الصوتية المرتبة الاخيرة بمتوسط بلغ 0,20 فقط.
10- انخفاض درجة الرضا عن الخدمات الارشادية بمنطقة الدراسة حيث وقع جميعهم في فئتي درجة الخدات

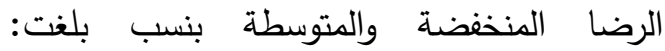
92,3\%، و 7,7 \% على الترتيب.

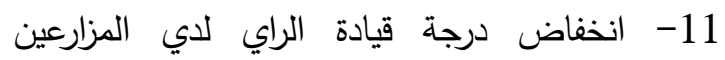

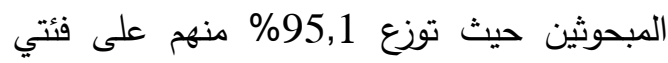

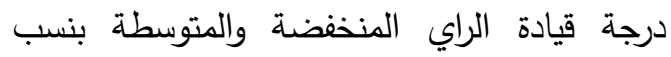
بلغت: 60,1\%، و 35\% على الترتيب.

ثانيا: المستوى المعرفي للمزارعين المبحوثين فيما يتعلق بالادارة المتكاملة للاراضي الملحية للمزارين المبية

تثير نتائج البحث (جدول رقم 3) الى ان أكثر من

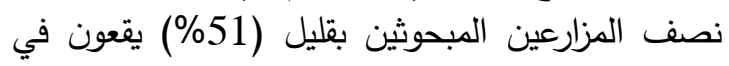

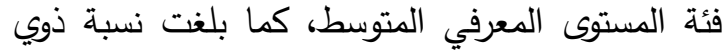

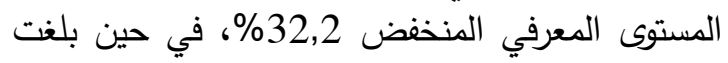

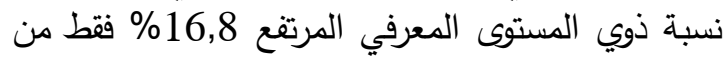

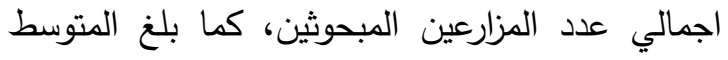
العام للمستوى المعرفي للمزارعين المبحوثين 0,42.

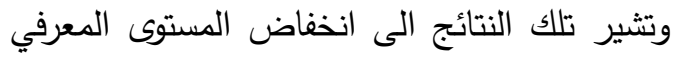

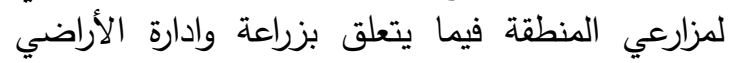

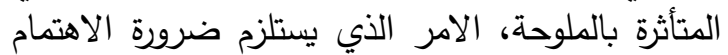

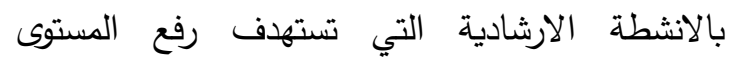

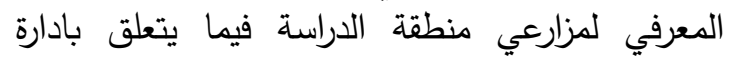

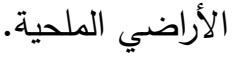

جدول 3. توزيع المزارعين المبحوثين وفقا لمستواهم المعرفي المتعلق بالادارة المتكاملة للاراضي الملحين

\begin{tabular}{|c|c|c|}
\hline$\%$ & $ت$ & المستوى المعرفي \\
\hline 32,2 & 46 & مستوى منخفض (اقل من 8 درجات) \\
\hline 51 & 73 & مستوى متوسط (من 8 - 14 درجة) \\
\hline 16,8 & 24 & مستوى مرتفع (15 درجة فاكثر) \\
\hline \multicolumn{2}{|c|}{0,42} & المتوسط العام \\
\hline
\end{tabular}

المصدر: نتائج الدراسة ن= 143 
جدول 5. الاهمية النسبية للطرق الارشادية من وجهة نظر المزارعين المبحوثين

\begin{tabular}{|c|c|c|c|c|c|c|c|c|}
\hline \multirow{2}{*}{ الترتيب } & \multirow{2}{*}{ المتوسط } & \multicolumn{2}{|c|}{ غير هامة } & \multicolumn{2}{|c|}{ هامة } & \multicolumn{2}{|c|}{ هامة جدا } & \multirow{2}{*}{ الطريقة } \\
\hline & & $\%$ & ت & $\%$ & ت & $\%$ & ت & \\
\hline 2 & 0,67 & 11,2 & 16 & 43,4 & 62 & 45,4 & 65 & الزيارات الحقلية \\
\hline 8 & 0,28 & 48,9 & 70 & 46,1 & 66 & 4,9 & 7 & الزيارات المكتبية \\
\hline 6 & 0,43 & 28 & 40 & 58 & 83 & 14 & 20 & المحاضرات الإرشادية \\
\hline 4 & 0,62 & 23,1 & 33 & 29,4 & 42 & 47,5 & 68 & الإيضاح العملى \\
\hline 7 & 0,38 & 37,1 & 53 & 48,9 & 70 & 14 & 20 & الندوات الإرشادية \\
\hline 5 & 0,58 & 19,6 & 28 & 44,7 & 64 & 35,7 & 51 & المطبوعات الإرشادية \\
\hline 3 & 0,65 & 9,8 & 14 & 49,6 & 71 & 40,6 & 58 & الأفلام التعليمية \\
\hline 1 & 0,74 & 6,3 & 9 & 39,1 & 56 & 54,5 & 78 & الممارسة تحت الاشراف \\
\hline 9 & 0,2 & 54,5 & 78 & 45,4 & 65 & 0 & 0 & التسجيلات الصوتية \\
\hline
\end{tabular}

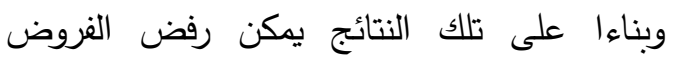

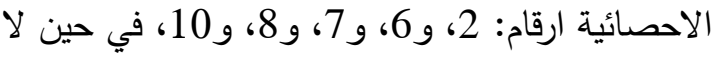

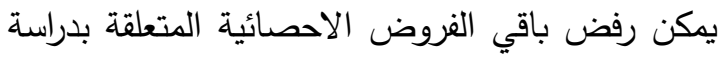

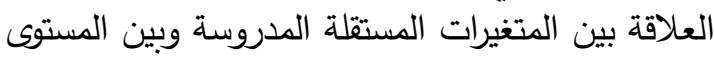

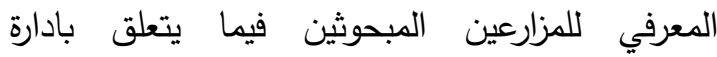

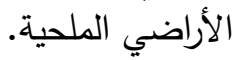

سادسا: علاقة بعض المتغيرات المستقلة للمزارعين

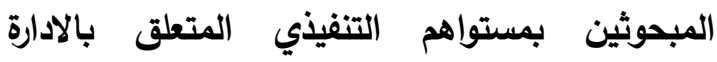
المتكاملة للاراضي الملحية: أوضحت نتائج البحث جدول رقم (7) وجود علاقة ارتباطية معنوية بين كل من المتغيرات البحات التالية: الخبرة

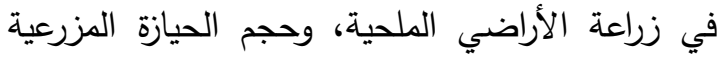

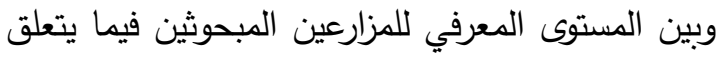

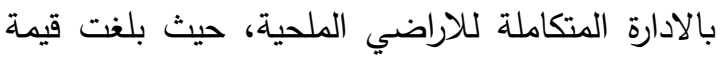
معامل الارتباط البسيط لبيرسون (0,53)، و(0,27) على الترتيب. كما أظهرت نتائج جدول رقم (7) وجود علاقة

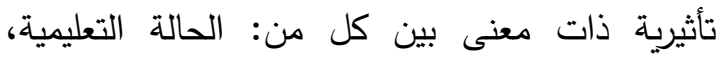

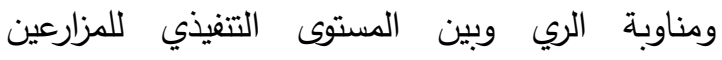

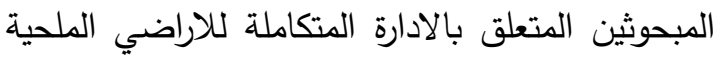
حيث بلغت قيمة معامل التوافق: (0,40)، و $(0,3)$

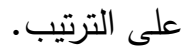

وتثير تلك النتئج الى اهمية التركيز على الجانب العملي الذي يستهدف الارتقاء بممارسات المزارعين في التئي

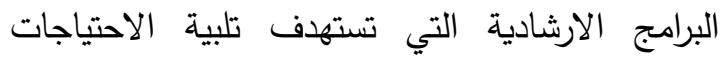
الارشادية المتعلقة بالادارة المتكاملة للاراضي المانية الملحية بمنطقة الدراسة.

خامسا: علاقة بعض المتغيرات المستقلة للمزارعين

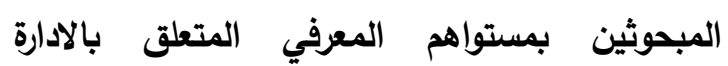
المتكاملة للاراضي الملحية

اوضحت نتائج البحث جدول رقم (6) وجود علاقة ارتباطية معنوية بين كل من المتغيرات التالية: الخبرة

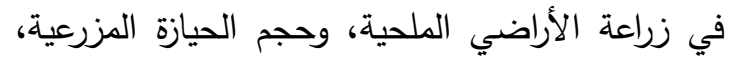

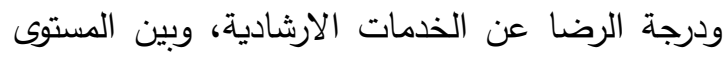

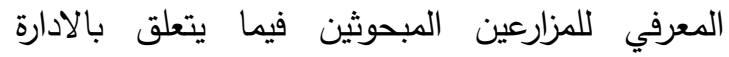

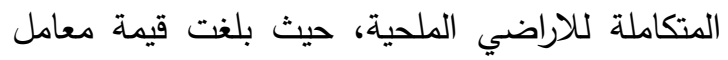

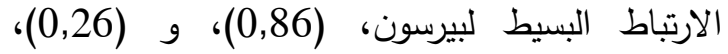
و (0,17) على الترتيب.

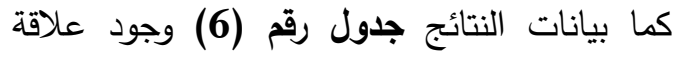

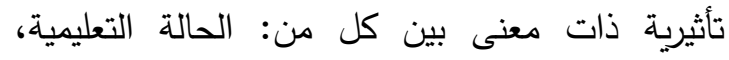

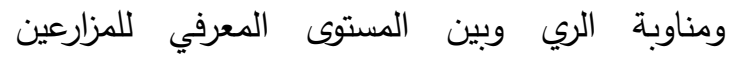
المبحوثين المتعلق بالادارة المتكاملة للاراضي الملينية حيث بلغت قيمة معامل التوافق : (0,64)، و التين (0,44) على الترتيب. 
جدول 6. علاقة بعض المتغيرات المستقلة للمزارعين المبحوثين بمستواهم المعرفي الدتعلق بالإدارة المتكاملة للأراضي الملحية بعضي المتئ.

\begin{tabular}{|c|c|c|c|}
\hline رقم الفرض & معامل التوافق & معامل الارتباط & المتفيرات \\
\hline 1 & & $0.21-$ & السن \\
\hline 2 & ${ }^{\star} 0.64$ & & الحالة التعليمية \\
\hline 3 & 0.10 & & النشأة \\
\hline 4 & & $0.14-$ & عدد أفراد الأسرة \\
\hline 5 & 0.04 & & ممارسة مهنة الزراعة قبل استلام الارض \\
\hline 6 & & $\star \star 0.86$ & الخبرة في زراعة الأراضي الملحية \\
\hline 7 & & ${ }^{\star \star} 0.26$ & حجم الحيازة المزرعية \\
\hline 8 & $\star \star 0.44$ & & مناوبة الري \\
\hline 9 & & 0.31 & درجة عضوية المنظمات الاجتماعية \\
\hline 10 & & ${ }^{\star} 0.17$ & درجة الرضا عن الخدمات الإرشادية \\
\hline 11 & & 0.02 & التجديدية \\
\hline 12 & & 0.04 & درجة قيادة الرأي \\
\hline
\end{tabular}

المصدر: نتائج التحليل الاحصائي لعينة الدراسة

جدول 7. علاقة بعض المتغيرات المستقلة للمزارعين المبحوثين بمستواهم التنفيذي المتعلق بالادارة المتكاملة للاراضي الملحية

\begin{tabular}{|c|c|c|c|}
\hline رقم الفرض & معامل التوافق & معامل الارتباط & المتغيرات \\
\hline 13 & & $0.09-$ & 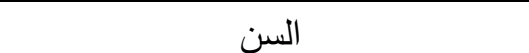 \\
\hline 14 & $\star \star 0.40$ & & الحالة التعليمية \\
\hline 15 & 0.04 & & 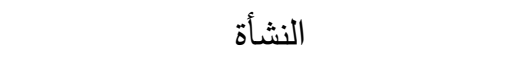 \\
\hline 16 & & $0.09-$ & عدد أفراد الأسرة \\
\hline 17 & 0.07 & & ممارسة مهنة الزراعة قبل استلام الارض \\
\hline 18 & & $\star \star 0.53$ & الخبرة في زراعة الأراضي الملحية \\
\hline 19 & & $\star \star 0.27$ & حجم الحيازة المزرعية \\
\hline 20 & $\star \star 0.3$ & & مناوبة الري \\
\hline 21 & & 0.12 & درجة عضوية المنظمات الاجتماعية \\
\hline 22 & & 0.12 & درجة الرضا عن الخدمات الإرشادية \\
\hline 23 & & 0.11 & التجديدية \\
\hline 24 & & $0.19-$ & درجة قيادة الرأي \\
\hline
\end{tabular}

المصدر: نتائج التحليل الاحصائي لعينة الدراسة 
- مين ذلك

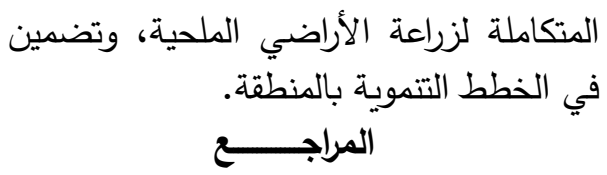

أولاً: المراجع باللغة العربية

أعضاء هيئة التدريس، محاضرات في الإرشاد

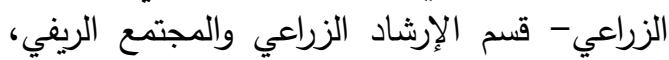

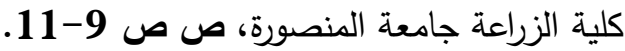
الخزرجي، رعد مسلم إسماعيل،

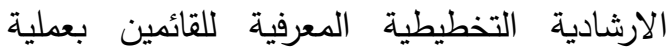
التخطيط الارشادي في الهيئات والشركات العامة

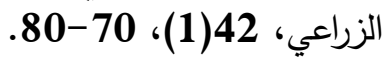

دراسة رصد وتقييم أوجه التنمية الزراعية الثاملة للمناطق المتاخمة لمسار ترعة السلام، 2015. مركز بحوث الصحراء، غير منشورة، القاهرة.

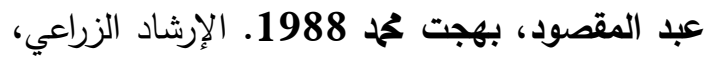

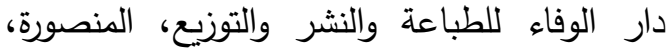
مصر، 9 ص.

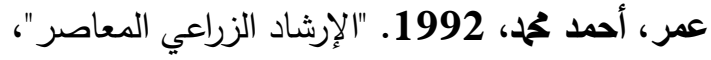
مصر للخدمات العلمية، القاهرة، مصر ، 48 صلإدادي

ثانياً: المراجع باللغة الانجليزية

Boydell, T.H. 1990. A Guide to the dentification of Training Needs. British Association for Commercial and Industrial Education, Second (Ed.) UK. 17 p.

Francis C.A. and Carter H.C. 2001. Participatory education for sustainable agriculture: Everyone a teacher, everyone a learner. Journal of Sustainable Agriculture, 18(1), 71-83.

Peterson, R. 1992. Training Needs Analysis in the Workplace. Institute of Training and Development, Kogan, UK, 16 p.

Radhakrishna, R. and Martin, M. 1999. Program evaluation and accountability training needs of agricultural extension agents. Journal of Extension, 37(3), 22.

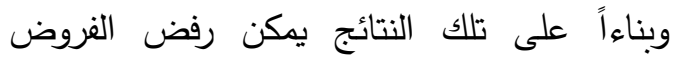

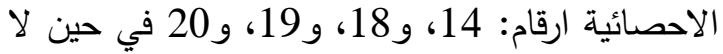

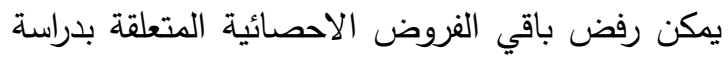

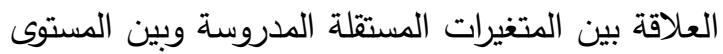
التنفيذي للمزارعين المبحوثين فيما ليتعلق بادارة

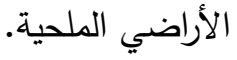
التوصيات

1- وفقاً لما اظهرته نتائج البحث من انخفاض

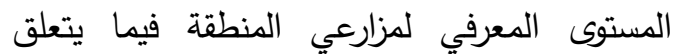

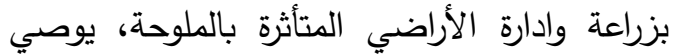
البحث بضرورة تدعيم الانشطة الارشادية التئي

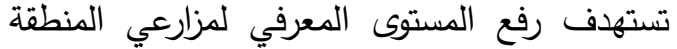

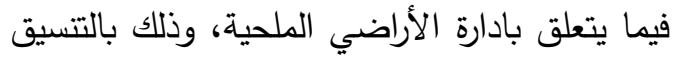

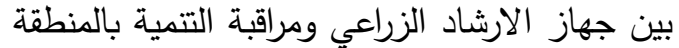
ومراكز البحوث المتخصصة والمعنية بخدمة اهالي المنطقة.

2- اتساقا مع ما ورد بنتائج البحث من انخفاض التواض مستوى تتفيذ المزارعين المبحوثين لتوصيات الادارة

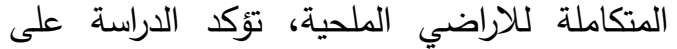
اهمية التركيز على الانثطة التدريبية الارشادية التي تستهدف رفع مهارات وقدرات المزارعين فيما يتعلق بالممارسات الجيدة لزراعة الأراضي المتأثرة

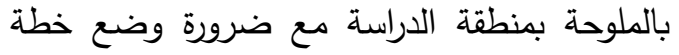

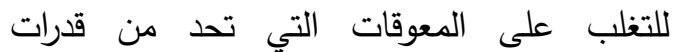
3- المزارعين في ادارة الأراضي الملحية.

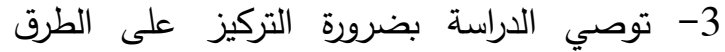
الارشادية العملية في تصميم البرامج الارشادية التي توري تستهدف الارتقاء بمستوى المزارعين فيما يتعلق الأرية بالادارة المتكاملة للاراضي الملحية. 4- توصي الدراسة بضرورة توفير الأكانيات والموارد اللازمة لاعم المزارعين في تطبيق حزمة الادارة 


\title{
THE EXTENSION NEEDS OF SAHL ALTINA'S FARMERS RELEVANT TO THE INTEGRATED FARM MANAGEMENT IN HIGHLY SALINE SOIL
}

\author{
Ibrahim, H.M. and A.O. Badawy \\ Agricultural Extension, Dept. Socio-Economic Division, Desert Research Center, \\ Cairo, Egypt
}

Keywords: The extension needs; Sahl Altina

\begin{abstract}
This study aimed at 1) identify level of both famers' knowledge and practices relevant to the integrated farm management in Sahl Altina as highly saline soil, 2) determine preferred extension methods from farmers point of view in the field of transferring highly saline soil recommendations, 3) identify correlation relationship between level of both famers' knowledge and practices relevant to highly saline soil and other farmers' socioeconomic characteristics.

Sahl Altina regoin was selected to conduct this study as highly saline soil. Three of the biggest famers' cooperatives in terms of participation number were selected to comprise the population of the study. A survey was carried out using interview questionnaire. A random sample of 143 farmers representing $10 \%$ of the total number of farmers were selected to conduct this study

Frequency tables, percentages, means were used for data presentation and analysis. contingency coefficient and Pearson correlation coeffi cients utilized to identify correlation relationship between level of both famers' knowledge and practices and other farmers' socioeconomic characteristics.

Findings of the study can be described as follows:

- There is Low level of both famers' knowledge and practices relevant highly saline soil.

- Demonstration under supervision was the most preferable method from farmers point of view.

- There is correlation relationship between famers' knowledge relevant to the integrated farm management in highly saline soil and the following: farming experience in highly saline soil, farm area, and satisfaction towards extension services.

- There is effect relationship between famers' knowledge relevant to the integrated farm management in highly saline soil and the following: education level and period of irrigation.

Finally, four recommendations were developed according the results of this study that may contribute to enhance extension work in the field of capacitate farmers with the integrated farm management under saline conditions
\end{abstract}

